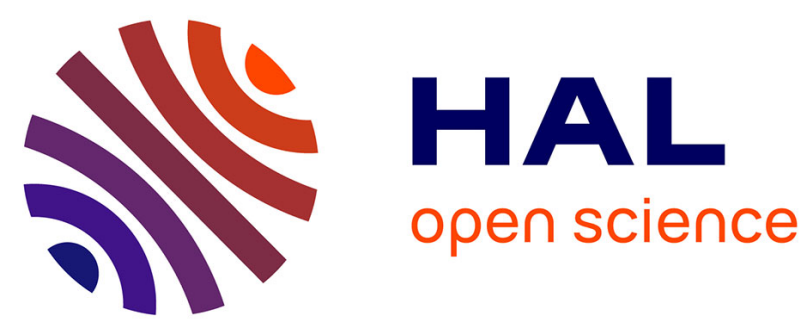

\title{
SELECTIVITY OF THE (13C, 13N), (13C, 13B) AND (12C, 12N) REACTIONS AT $30 \mathrm{MeV} / \mathrm{n}$
}

\author{
W. von Oertzen, E. Adamides, H. Bohlen, A. Miczaika, E. Stiliaris, M. \\ Buenerd, J. Chauvin, D. Lebrun, J.Y. Hostachy, Ph. Martin, et al.
}

\section{- To cite this version:}

W. von Oertzen, E. Adamides, H. Bohlen, A. Miczaika, E. Stiliaris, et al.. SELECTIVITY OF THE $(13 \mathrm{C}, 13 \mathrm{~N}),(13 \mathrm{C}, 13 \mathrm{~B})$ AND $(12 \mathrm{C}, 12 \mathrm{~N}) \mathrm{REACTIONS}$ AT $30 \mathrm{MeV} / \mathrm{n}$. International Conference on Heavy Ion Nuclear Collisions in the Fermi Energy Domain,Hicofed 86, 1986, Caen, France. pp.C4175-C4-178, 10.1051/jphyscol:1986420 . jpa-00225786

\section{HAL Id: jpa-00225786 https://hal.science/jpa-00225786}

Submitted on 1 Jan 1986

HAL is a multi-disciplinary open access archive for the deposit and dissemination of scientific research documents, whether they are published or not. The documents may come from teaching and research institutions in France or abroad, or from public or private research centers.
L'archive ouverte pluridisciplinaire HAL, est destinée au dépôt et à la diffusion de documents scientifiques de niveau recherche, publiés ou non, émanant des établissements d'enseignement et de recherche français ou étrangers, des laboratoires publics ou privés. 
JOURNAL DE PHYSIQUE

Colloque C4, supplément au $n^{\circ} 8$, Tome 47 , août 1986

SELECTIVITY OF THE $\left({ }^{13} \mathrm{C},{ }^{13} \mathrm{~N}\right),\left({ }^{13} \mathrm{C},{ }^{13} \mathrm{~B}\right)$ AND $\left({ }^{12} \mathrm{C},{ }^{12} \mathrm{~N}\right)$ REACTIONS AT $30 \mathrm{MeV} / \mathrm{n}$

W. VON OERTZEN, E. ADAMIDES, H.G. BOHLEN, A. MICZAIKA,

E. STILIARIS, M. BUENERD* , J. CHAUVIN* , D. LEBRUN*

J.Y. HOSTACHY* , Ph. MARTIN*, G. PERRIN* and P. DE SAINTIGNON*

Hahn-Meitner-Institut, D-1000 Berlin 39, F.R.G.

- Institut des Sciences Nucleaires, 53, Avenue des Martyrs, F-38026 Grenoble, France

Abstract - Charge exchange reactions induced by ${ }^{12} \mathrm{C}$ and ${ }^{13} \mathrm{C}$ are discussed on a ${ }^{12} \mathrm{C}$ target nucleus. Comparison of cross sections for the population of dicrete states and of the continuum gives information which determines the selectivity of these reactions with respect to various modes with and without spin-flip.

The reactions $\left({ }^{13} \mathrm{C},{ }^{13} \mathrm{~N}\right)$ and $\left({ }^{12} \mathrm{C},{ }^{12} \mathrm{~N}\right)$ offer new possibilities to study isovector modes in nuclei. The main interest lies in the possibility to realise " $(n, p)$ " reactions with spin-flip $(\Delta S=1)$ and without $(\Delta S=0)$ at the same dynamical conditions. Experiments for these reactions haye been performed the accelerators SARA (Grenoble) and VICKSI (Berlin) for the $\left({ }^{13} \mathrm{C},{ }^{3} \mathrm{~N}\right)$ and $\left({ }^{12} \mathrm{C},{ }^{12} \mathrm{~N}\right)$ reactions.

The results on the ${ }^{12} \mathrm{C}$ target give a particularly clear insight into the properties of these reactions, because the levels in the nuclei $12 \mathrm{~N}$ and ${ }^{12} \mathrm{~B}$ are well separated and their structure, is well known. In figs. 1 to 3 we show spectra of the $\left({ }^{13} \mathrm{C},{ }^{13} \mathrm{~N}\right)$, or ${ }^{12} \mathrm{~N}$ as residual nuclei should be equal because these nuclei are mirror nuclei. There are several conspicuous differences in these spectra, which can be assessed in a quantitative way. The first point concerns the population of the spin-flip states $1^{+}$and $2^{-}$. The Gampy-Teller transition $(l=0, \Delta s=1)$ leading to the $1^{+}$state is well separated in the $\left({ }^{12} C,{ }_{N}\right)$ spectra, it is observed as a shoulder in the two other cases. In order to compare the cross sections we calculate the Q-value dependence by using a macroscopic formfactor (see fig. 4). Because of the more negative Q-values the $\left({ }^{13} C,{ }^{3} \mathrm{~B}\right)$ and $\left({ }^{12} \mathrm{C},{ }^{12} \mathrm{~N}\right)$ reactions have less cross section in the total spectrum. The cross sections for the $1^{+}$states at $\theta \mathrm{CM}=10^{0}$ recalculated to the $\left({ }^{3} \mathrm{C},{ }^{13_{N}}\right) \mathrm{Q}$-value are given for the most prominent peaks in table 1 . For the spinflip transitions these cross sections are favoured in the case of $\left({ }^{i 2} \mathrm{C},{ }^{12} \mathrm{~N}\right)$ and $\left({ }^{1} \mathrm{C}, 13 \mathrm{~B}\right)$ and the non spin-flip transitions are extremely surpressed in the case of $\left({ }^{12} \mathrm{C},{ }^{12} \mathrm{~N}\right)$. The cross sections of the two former reactions for the $1^{+}$and $2^{-}$states are very close and can be related to the logft values of the corresponding $\beta$-decays $\left(3_{B}\right.$ logf $=4.9_{3}{ }^{2} \mathrm{~N}$ logft $=4.1,{ }^{3} \mathrm{~N}$ logft=3.7), they compare favorable with results for for $\left({ }^{12} \mathrm{C}, \mathrm{I}_{\mathrm{N}}\right)$ at $35 \mathrm{MeV} / \mathrm{u}$ (ref. 1 ).

Table 1: Cross sections for transitions leading to final states of ${ }^{12} \mathrm{~B}$ and ${ }^{12} \mathrm{~N}$ at $\theta_{\mathrm{cm}}=10^{\circ}$

\begin{tabular}{crr|rr|rr|rr|} 
reaction & $1^{+}$ & $\bar{\sigma}$ & $2^{+}$ & $\bar{\sigma}$ & $2^{-}$ & $\bar{\sigma}$ & $1^{-}$ & $\bar{\sigma}$ \\
\hline$\left({ }^{13} \mathrm{C}, 13 \mathrm{~N}\right)$ & 25 & 25 & 80 & 80 & 120 & 120 & 160 & 160 \\
$(12 \mathrm{C}, 12 \mathrm{~N})$ & 6 & 38.8 & 3.4 & 10.9 & 30 & 162 & 12 & 60 \\
$\left({ }^{3} \mathrm{C}, 13 \mathrm{~B}\right)$ & 12 & 76 & 35 & 112 & 170 & 920 & 200 & 1080
\end{tabular}


$\bar{\sigma}$ cross sections corrected to the $Q$-value of the $\left({ }^{13} \mathrm{C},{ }^{13} \mathrm{~N}\right)$ reaction. Units are $[\mu \mathrm{b} / \mathrm{sr}]$; The spin assignments are for the prominent peaks.

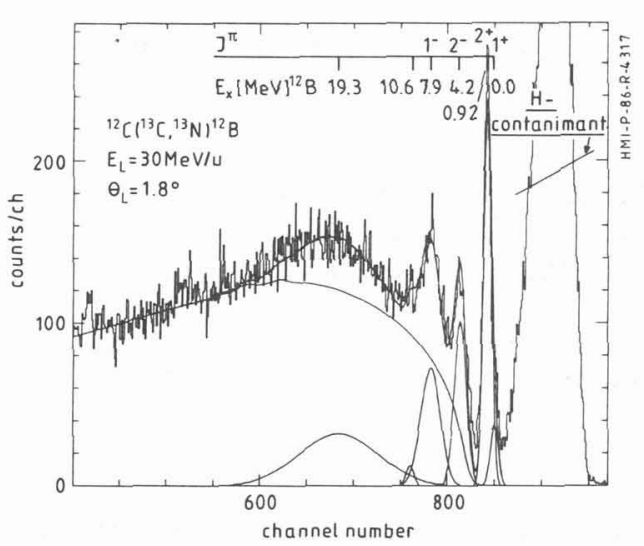

Fig. 1

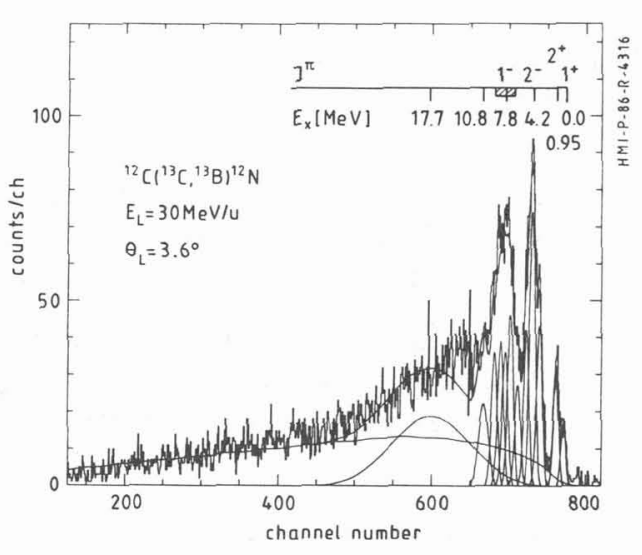

Fig. 2

The second important point is the population of higher lying states and the continuum. We have made calculations for the three body continua by assuming that the main strength for the $(p, n)$ reaction passing through states of ${ }^{14} \mathrm{~N}$ or ${ }^{13} \mathrm{~N}$ for the $\left({ }^{3} C^{14} N^{*}\right) \rightarrow\left({ }^{13} C,{ }^{13} N^{N+n}\right)$ reaction) will come from states with properties like the Giant Dipol resonance these are located at ca. $22.5 \mathrm{MeV}$ and we use a width of $5 \mathrm{MeV}$. The three body continuum is calculated with a program which has been described in ref. 2. The fit is made in such a way that the continuous part of a spectrum extending to high excitation is fully reproduced (see figs. 1-3). The curyes in the figures for the "background" are such calculations. In the case of $\left({ }^{13} \mathrm{C},{ }^{3} \mathrm{~N}\right)$ it is also possible to get a different shape of the background by a structured $(p, n)$ strength in ${ }^{4} \mathrm{~N}$. However, inspection of all three spectra suggest that the continuum we observe in the three spectra - i.e. the particluar differences, can only be explained if we assume that the strength in the spectra is not due to pick-up decay contributions but to the two body charge exchange reactions. The arguments are as follows:

1) Comparison of $\left({ }^{13} \mathrm{C},{ }^{13} \mathrm{~N}\right)$ and and $\left({ }^{12} \mathrm{C},{ }^{12} \mathrm{~N}\right)$ spectra

The pick-up decay cross sections must be given by states in ${ }^{14} \mathrm{~N}$ or ${ }^{13} \mathrm{~N}$ which are are strongly populated by proton stripping and which decay by neutron emission (excitation function of $(p, n)$ on the projectile in the case of " $(n, p)$ " reaction and corresponding the $(n, p)$ excitation function on the projectile for " $(p, n)$ " reactions). The reactions will not differ strongly for ${ }^{12} \mathrm{C}$ and ${ }^{13} \mathrm{C}$ projectiles; the Q-value difference is $5.8 \mathrm{MeV}$, the effect on the cross sections gives for the case of ${ }^{13} \mathrm{C}$ induced reactions a factor 1.6 larger cross section. The experimental "background" cross section in the reaction $\left({ }^{12} \mathrm{C},{ }^{12} \mathrm{~N}\right)$ is however by a factor 20 smaller that in the $\left({ }^{13} \mathrm{C},{ }^{13} \mathrm{~N}\right)$ case.

2) Comparison of the $\left({ }^{13} \mathrm{C},{ }^{13} \mathrm{~N}\right)$ and $\left({ }^{13} \mathrm{C},{ }^{13} \mathrm{~B}\right)$ spectra. In the case of $\left({ }^{13} \mathrm{C},{ }^{13} \mathrm{~B}\right)$ we observe cross sections for discrete states (table 1 ) which are comparable to $\left({ }^{13} \mathrm{C},{ }^{13} \mathrm{~N}\right)$ if we consider the non spin-flip states like $2^{+}$and $1^{-}$(factor 2 for the multiplicity difference has to be considered and the correction for Q-value dependence).

The spin-flip states are favoured in the $\left({ }^{13} \mathrm{C},{ }^{13} \mathrm{~B}\right)$ case by a factor 2 . Using this information we would predict for the high lying states, the same average cross section for both reactions (using the calculated Q-value dependence, the difference of the total Q-value is ca. $15 \mathrm{MeV}$ ). This is actually observed as indicated for the $B G D$-cross sections in $f i g .5$. In this particular case the contributions from the three, body continuum, pick-up of a neutron and decay by proton emission from ${ }^{4} \mathrm{C}$ to for ${ }^{13} \mathrm{~B}$, are likely to be completely negligible. Nevertheless the curves in fig. 2 
are calculated by a three-body continuum calculation in the same way as in the $\left.{ }^{[3} \mathrm{C},{ }_{N}\right)$ case in order to have a quantiative comparison.

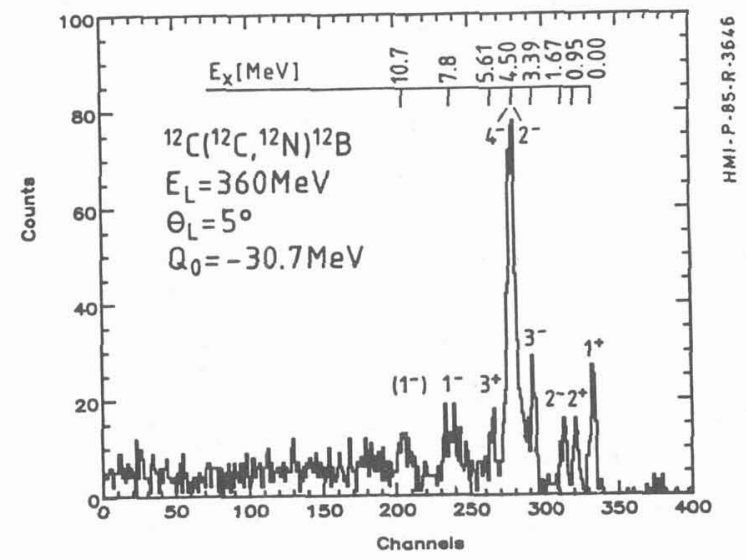

Fig. 3

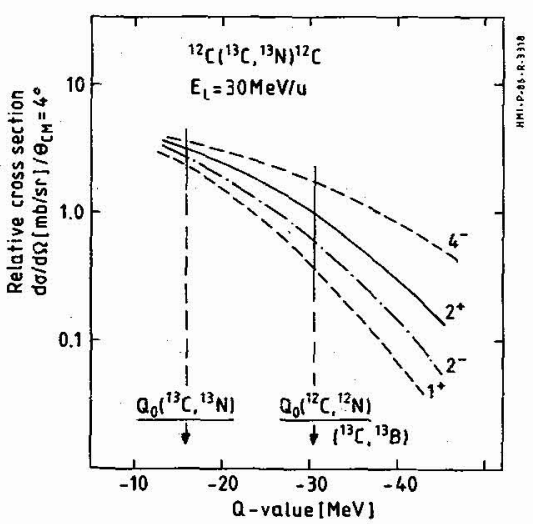

Fig. 4 - Q-value dependence of charge exchange reactions.

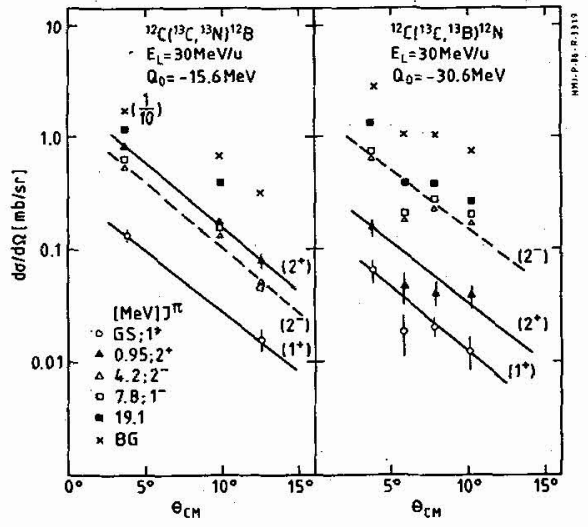

Fig. 5 - Experimental cross sections (angular distributions).

We therefore conclude that the differences in "background" in the three spectra can be perfectly explained by the different or equal selectivity of the two-body charge exchange reactions with the inclusion of the $Q$-yalue dependence of these reactions. The reduced cross sections in the case of $\left({ }^{1}{ }_{C},{ }_{2}\right)$ are consistently explained by the very strong selectivity with respect to spin-flip transition and therefore numbers of states in the continuum. The structure, which we find at ca. 18-20 MeV excitation which looks like a giant resonance is consistently observed in the two reactions, where non spin-flip states are populated. This structure could therefore be due to the giant isovector quadrupole resonance in mass 12 .

If we finally inspect the angular distributions in fig. 5 we find that the differences between different states and the two ${ }^{13} \mathrm{C}$ reactions are smal1. Data with better energy resolution and smaller angle steps are needed to distinguish shapes corresponding to different multipolarity. 


\section{REFERENCES}

/1/ J.S. Wienfield et a1. Phys. Rev. C33 (1986) 1333

12/ H.G. Bohlen et al. Z. für Physik A320 (1985) 237 